\title{
Technical Efficiency of Maternal Health Services Provision in Public Hospitals of Northwest Ethiopia: A Two-Stage Data Envelopment Analysis
}

This article was published in the following Dove Press journal: Risk Management and Healthcare Policy

\section{Tsegaw Amare \\ Mezgebu Yitayal (D) \\ Getasew Amare (D)}

Department of Health Systems and Policy, Institute of Public Health, College of Medicine and Health Sciences, University of Gondar, Gondar, Ethiopia
Correspondence: Getasew Amare Department of Health Systems and Policy, Institute of Public Health, College of

Medicine and Health Sciences, University of Gondar, PO Box - 196, Gondar,

Ethiopia

Tel +251910151944

Email getasewa23@gmail.com
Introduction: Ethiopian health expenditure as a share of total government expenditure increased from $7.6 \%$ in $2013 / 14$ to $8.1 \%$ in $2016 / 17$. But it remained low even for the lowincome country average expected share of $8.7 \%$. It signifies the efficient use of scarce resources in the health sector is still critical to achieving sustainable development goals. But little evidence is available about public hospitals' technical efficiency in providing maternal health services. Therefore, the aim of this study was to assess the technical efficiency of maternal health services provision of public hospitals in Northwest Ethiopia.

Methods: Facility-based cross-sectional study was conducted among twelve randomly selected public hospitals. Input data (salary expenditure, non-salary expenditure, and the number of beds) and maternal health services output data (antenatal care, skilled delivery, and postnatal care) for a 2011 Ethiopian fiscal year (July 2018 to June 2019) were collected and entered into Epi-Data 3.1. We used both primary and secondary data collection procedures to determine independent variables and the dependent variable, respectively. We also used a two-stage input-oriented data envelopment analysis with variable returns to scale assumption.

Results: The study showed that hospitals included in this study wasted US\$ 6833.50 for salary and US\$ 3886.8 for non-salary expenditures. The study also revealed that the mean pure technical efficiency of public hospitals for maternal health service provision was 0.92 \pm 0.142 , and their scale efficiency was $0.795 \pm 0.24$. The hospital manager's experience year, the educational level of the manager, and the hospital service year associated positively with the technical efficiency. However, the catchment population and distance of another health facility associated negatively with technical efficiency.

Conclusion: The public hospitals' pure technical efficiency in the provision of maternal health services in Northwest Ethiopia was high. More than half of the public hospitals were technically efficient. The wasted amount of expenditures could be used for satisfying the unmet health services need of the population. Therefore, it is better to monitor the health facilities for the wise use of the existing resources for their best performance.

Keywords: technical efficiency, maternal health service, public hospitals, data envelopment analysis, tobit model, Northwest Ethiopia

\section{Introduction}

Maternal health service is recognized as a good measure of overall population health and health system performance, particularly in low-income countries. ${ }^{1}$ Globally, in 2015, 300,000 pregnant women died, with more than half from SubSaharan Africa. ${ }^{2}$ The 2016 Ethiopian demographic and health survey reveals Ethiopia has high maternal mortality with 412 per 100,000 live births estimated 
ratio. $^{3}$ It is very far from the sustainable development goal (SDG) of reducing the maternal mortality ratio by less than 70 per 100,000 live births by $2030 .^{4}$

Ethiopia is among one of the low-income countries with a low budget allocation for health care delivery. The seventh and recent Ethiopian health account showed that the country's health expenditure as a share of total government expenditure increased from $7.6 \%$ in $2013 / 14$ to $8.1 \%$ in $2016 / 17 .^{5}$ But it remained low even for the low-income country average expected share of $8.7 \%$. It indicates the efficient use of scarce resources in the health sector is critical to achieving the stated SDG.

Even though there is an increasing interest among health policymakers in Africa towards efficient utilization of health resources, ${ }^{6,7}$ there are indicators for the inefficient utilization of resources. An input-based budgeting system ${ }^{8}$ and the absence of real competition ${ }^{9}$ can be used as sources of inefficient performance of public hospitals. However, It is underlined that the efficient utilization of resources is one of the stressing points on moving towards universal health coverage, ${ }^{10}$ and ensuring efficiency is one priority area of the Ethiopian health sector transformation plan. ${ }^{11}$

Technical efficiency is one of the widely used efficiency assessment approaches for health facilities. It is the best-observed practice achieved by the decisionmaking unit (DMU) on converting physical inputs into outputs, which is determined by the difference between the observed ratio of combined quantities of DMU output to input. ${ }^{12}$ It is affected by the size of operations (scale efficiency) and by managerial practices (pure technical efficiency). ${ }^{13}$

The technical efficiency of huge stakeholders in the health sector is critical for achieving the SDG of the maternal mortality ratio. Hospitals are one of the huge and ultimate decision-making units (DMUs) for costeffective and efficient health service provision to achieve universal health coverage and sustainable development goals. So, they need to ensure that these health facilities provide efficient health services.

Although technical efficiency is in extensive use in the rest of the world ${ }^{14-18}$ to elucidate health facilities' performance, only a few studies have been conducted in Ethiopia. Even if different studies were conducted in Ethiopia, ${ }^{19}$ they did not select the appropriate input and output data relative to DMUs and did not assess the factors associated with technical efficiency. ${ }^{20}$

This study was conducted by addressing the limitation of the previous studies by selecting a small number of inputs and outputs and also identifying factors in the second stage of data envelopment analysis. It is also specific for maternal health services to make focused evidence for policymaking towards SDG achievement of maternal mortality ratio. Moreover, this method did not previously apply elsewhere in the health systems of Northwest Ethiopia. Therefore, this study aimed to assess public hospitals' technical efficiency towards maternal health services provision in Northwest Ethiopia.

\section{Materials and Methods Study Design and Period}

We conducted a facility-based cross-sectional study from February 15 - March 15, 2020, to assess public hospitals' technical efficiency in providing maternal health services and associated factors in the Northwest of Ethiopia. This study's source population was all public hospitals in the four districts of Northwest Ethiopia. Whereas, the study population for this study was all selected public hospitals in four districts of Northwest Ethiopia. The public hospitals which were functional in the 2011 Ethiopia fiscal year were included in the study.

\section{Study Settings}

The study was conducted on public hospitals of Northwest Ethiopia. Ethiopia's health system structure is organized with the three-level health care system since $2010 .^{21}$ The primary level includes the health post, health center, and primary hospital. The secondary level consists of the general hospitals, and the tertiary level consists of specialized hospitals. Maternal health services in primary health care are mainly preventive, non-emergency services, and essential obstetric care. In the secondary level, emergency obstetric services are included. The tertiary level provides comprehensive emergency and non-emergency maternal health services. $^{22}$ The Northwest Ethiopia where the study was conducted has four districts (the Central Gondar district, the North Gondar district, the West Gondar district, and the South Gondar district), and 20 public hospitals (one referral, one general, and 18 primary hospitals).

\section{Sample Size Determination and Sampling Procedures}

Based on the WHO "tool for assessing the operationality of district health systems" ${ }^{\text {,23 }}$ recommendation, since districts in Northwest Ethiopia are fewer than nine, all (four) 
districts were included, and 12 public hospitals out of 20 public hospitals on the districts were randomly selected. The public hospitals were proportionally allocated based on the level of hospitals. Using the lottery method, one referral, one general, and ten primary hospitals were selected accordingly. The calculated number of hospitals determined the number of inputs and outputs to be included in the study. We selected three inputs and three outputs to be in line with the rule that the number of inputs should be less than one-third of the number of DMUs, and the number of DMUs should be greater than the product of the number of outputs and inputs ${ }^{24}$ or greater than two times the sum of inputs and outputs. ${ }^{25}$

\section{Variables}

The dependent variable of this study was the technical efficiency of maternal health services provision in public hospitals. The output variables were the number of antenatal care (ANC) visits, skilled delivery, and postnatal care (PNC) services provided in public hospitals. The input variables were salaried expenditure, non-salary expenditure, and a number of beds to provide maternal health services. Inputs as a factor of production are summarized into two categories; labor and capital. Salary expenditure is used as a proximate measure of labor, whereas nonsalary expenditures and the number of beds were used as the proximate measure of materials and capital, respectively.

The independent variables were organizational factors: managerial service years of the CEO, the CEO's educational status, the distance of the CEO's residence from the facility, additional benefit packages for the employees, level of facility, service year of facility, and patient waiting time. And environmental factors were total catchment population, the availability of nearby health facilities, and the distance of the facility from the capital city.

This study's one fiscal year includes the time from July 8, 2018, to July 7, 2019. The maternal health service was ANC service, skilled delivery, and PNC service. The ANC services included were the first and fourth ANC visits, and skilled delivery could be any type of child delivery service provided by the facility.

\section{Data Collection Tools and Procedures}

Both primary and secondary data collection procedures were employed in this study. A structured and pretested questionnaire that contains questions on the environmental and organizational related characteristics was used for primary data collection. The document review was used for the secondary data collection on the inputs for maternal health services and the maternal health services outputs in each hospital's 2011 Ethiopian fiscal year.

The questionnaire was developed after reviewing the standards for the public hospitals of the country, ${ }^{22}$ the WHO tool for assessing the operationality of district health systems, ${ }^{23}$ and related literature. ${ }^{19,26}$ Specifically, the output data were obtained from the district health information system 2 (DHIS-2) database from the respective hospitals to ensure data reliability. ${ }^{27}$

\section{Data Quality Control}

The tool was prepared in English, then translated into Amharic, and then back-translated into English to check for its consistency. Four data collectors with a bachelor's degree in health science background were recruited. A day of training was given for the data collectors before the actual data collection period, and a pretest of the tool was conducted at Addis Zemen health center. Then, the tool's error was identified, especially the starting and ending point of the questionnaire was rearranged, and unclear words were corrected accordingly. Every day after data collection, questionnaires were reviewed and checked for their completeness and relevance by the principal investigator. Then the necessary feedback was offered to data collectors the next morning.

\section{Data Management}

We used the volume method of indirect cost estimation to determine a specific expenditure value for the specified outputs produced, which counts the ratio of the number of maternal health services to the operational cost multiplied the total number of services. The procedure was conducted to identify specific expenditures for the defined common inputs shared to provide health services, including maternal health services. The cost of particular inputs for maternal health services (midwife nurses, physicians for maternal health services, and beds for maternal health services) was counted separately. Finally, the inputs for maternal health services were calculated by the sum of the shared amount of inputs and the specific inputs for maternal health services.

Expenditures in Ethiopian birr were changed to the US dollar with an exchange rate of 1 Ethiopian birr to 0.0295 US dollars by the date February $2019 .{ }^{28}$ Costing was done from the provider perspective, and bottom-up costing was employed. Data were collected, entered into EpiData 
version 3.1, and exported to Microsoft excel 2019 and STATA software version 14 for further analysis.

\section{Data Analysis}

The two most widely used analysis methods for measuring technical efficiency are stochastic frontier analysis and data envelopment analysis (DEA). The former is the parametric measurement and uses econometric approaches to estimate the functional forms towards measuring output to input. The latter is a non-parametric approach, which is a flexible method that uses observed data to determine the frontier without placing conditions on the user form for multiple outputs and inputs. ${ }^{29}$

The DEA works on relative and ratio-based analysis. The relative performance proved to be technically efficient if and only if the other DMUs with the same inputs and outputs do not show inputs and outputs can be improved without worsening some of the other inputs and outputs. ${ }^{30}$

In DEA, technical efficiency is calculated as the bestobserved practice achieved by the DMU on converting physical inputs into outputs, determined by the observed ratio of combined quantities of an entity's output to input. $^{12}$

$\begin{aligned} & \text { Technical } \\ & \text { efficiency }\end{aligned}=\frac{\text { The weighted sum of outputs produced }}{\text { The weighted sum of inputs used }}$

In this study, the two-stage DEA was used to identify public hospitals' technical efficiency and associated factors on maternal health services. It is the best way of technical efficiency analysis for multiple inputs and multiple outputs.

The DEA assumes the two technical efficiency assessment methods, the VRS with Banker, Charnes, and Cooper model, and CRS with Charnes, Cooper, and Rhodes model.

The choice of CRS or VRS usually depends on the context and purpose of the analysis. If the interest is only in productivity regardless of the scale of operations, CRS be more appropriate. If the attention is focused on how the scale of operations affects productivity, VRS be preferred, particularly if it is believed that DMUs are not operating at their optimal scales. ${ }^{31}$

Technical efficiency can be expressed as the potential to increase outputs from given quantities of inputs, the socalled output-oriented technical efficiency, or the potential to reduce the quantities of inputs used in producing given quantities of outputs input-oriented technical efficiency. It is affected by the size of operations (scale efficiency) and by managerial practices (pure technical efficiency). ${ }^{13}$

In this study, in the first stage, DEA with input orientation and VRS assumption was conducted by the DEA program version 2.1 (DEAP 2.1) developed by Tim Coelli. $^{32}$

The input orientation was selected because the public hospitals can influence the inputs more than the outputs as there is no real competition among public hospitals, and their primary goal is to provide curative services. Besides, the output of public hospitals is need-based from the beneficiaries, which cannot be within their primary control. The VRS assumption is preferred because not all analysis units are considered to be operating at an optimal scale as the study done on public hospitals where financial constraints are typical, leading to not working on their optimal scales.

The VRS takes two forms: decreasing returns to scale (DRS) and increasing returns to scale (IRS). The DRS implies that a health facility is large for its operation scale, so it needs to downsize its operation to be scale efficient. The hospital performing the IRS needs to enlarge its level of service to become scale efficient since its size is small for its operation scale. ${ }^{12}$

The formula derived by Cooper $^{33}$ for the VRS inputorientated DEA was used to compute each public hospital's relative technical efficiency towards the maternal health service production based on the expended inputs.

$$
\text { Efficiency }=\max \sum_{\vec{r}} U_{r} y_{r j^{0}}+U 0
$$

Subject to

$$
\begin{gathered}
\sum_{r} U_{r} y_{r j}-\sum_{r} V_{i} X_{i j}+\mathrm{U}_{0} \leq 0 ; j=1, \ldots, n \\
\sum_{i} v_{i} x_{i j j^{0}}=1 \\
U_{r}, V_{i} \geq 0
\end{gathered}
$$

Where:

$\mathrm{y}_{\mathrm{r} j}=$ the amount of the output $\mathrm{r}$ produced by health facility $\mathrm{j}$,

$X_{i j}=$ the amount of the input $i$ used by health facility $j$,

$\mathrm{U}_{\mathrm{r}}=$ the weight given to the output $\mathrm{r},(\mathrm{r}=1 \ldots \mathrm{t}$ and $t$ is the number of outputs),

$\mathrm{V}_{\mathrm{i}}=$ the weight given to the input I, $(\mathrm{I}=1$ ... $\mathrm{m}$ and $\mathrm{m}$ is the number of inputs),

$\mathrm{j}_{0}=$ the health facility under assessment. 
As the second stage of the DEA, the Tobit regression model was used to identify the factor affecting public hospitals' technical efficiency in providing maternal health services. As the ordinary least square regression leads to biased estimation due to the censoring of the data, Tobit regression remains the choice of analysis for the dependent variable with censored datasets, although the debate on the choice of regression analysis ongoing among scholars. ${ }^{34}$ Significant factors were determined at a p-value of less than 0.05 and a $95 \%$ confidence level.

\section{Results}

\section{Organizational Factors}

All selected public hospitals were assessed for this study, making a response rate of $100 \%$. The study revealed that all heads of the facilities were males, and $9(75 \%)$ had less than five years of experience. Out of 12 heads of the facilities, half of them had a Master's and above degree.

The study showed that $8(66.67 \%)$ facilities were recently opened with less than five years of operation regarding the facilities. In $10(83.33 \%)$ public hospitals, patients had to wait 30 minutes and more at the outpatient department to get services from the hospitals (Table 1).

\section{Environmental Factors}

Regarding the environmental factors, the study showed that $5(41.67 \%)$ of the hospitals had a catchment population of greater than one million, and $10(83.33 \%)$ of hospitals had another health facility that gives maternal health service within a two-kilometer distance (Table 2).

\section{Inputs Used and Outputs Produced}

This study showed that a total of US\$ 2,303,706 and US $\$ 477,534.5$ amount of salary and the non-salary cost was expended for the 2011 Ethiopian fiscal year, and 297 beds were used for the ANC, delivery, and PNC services in the study hospitals (Supplementary Material).

The study also showed that the 12 hospitals provided 31,892, 26,723, and 16,346 numbers of ANC, Skilled delivery, and PNC service in the fiscal year (Table 3).

\section{The Efficiency Score of Public Hospitals}

The study revealed that $7(58.3 \%)$ hospitals were pure technical efficiency, and $5(41.67 \%)$ of the hospitals were scaled as efficient (Figure 1). Out of scale inefficient hospitals, $3(25 \%)$ were operating beyond their scale, whereas $4(33.33 \%)$ were operating below their level.
Table I Organizational Factors of Public Hospitals Towards Maternal Health Services at the Northwest of ANRS, Ethiopia, 2020 ( $N=12$ DMUs)

\begin{tabular}{|c|c|c|c|c|}
\hline No & Variables & Category & $\begin{array}{l}\text { Frequency } \\
\text { (N) }\end{array}$ & $\begin{array}{l}\text { Percent } \\
\text { (\%) }\end{array}$ \\
\hline I & Sex of the CEO & Male & 12 & 100 \\
\hline 2 & Age of the CEO & $\begin{array}{l}<30 \\
\geq 30\end{array}$ & $\begin{array}{l}4 \\
8\end{array}$ & $\begin{array}{l}33.33 \\
66.67\end{array}$ \\
\hline 3 & $\begin{array}{l}\text { Educational status } \\
\text { of the CEO }\end{array}$ & $\begin{array}{l}\text { BSc } \\
\geq \text { Master }\end{array}$ & $\begin{array}{l}6 \\
6\end{array}$ & $\begin{array}{l}50.00 \\
50.00\end{array}$ \\
\hline 4 & $\begin{array}{l}\text { Managerial } \\
\text { service year of the } \\
\text { CEO }\end{array}$ & $\begin{array}{l}\leq 5 \text { years } \\
>5 \text { years }\end{array}$ & 3 & $\begin{array}{l}75.00 \\
25.00\end{array}$ \\
\hline 5 & $\begin{array}{l}\text { Distance from the } \\
\text { hospital to the } \\
\text { CEO's residence }\end{array}$ & $\begin{array}{l}<2 K M \\
\geq 2 K M\end{array}$ & 6 & $\begin{array}{l}50.00 \\
50.00\end{array}$ \\
\hline 6 & $\begin{array}{l}\text { Hospitals provide } \\
\text { staff with additional } \\
\text { cash benefits* }\end{array}$ & $\begin{array}{l}\text { Yes } \\
\text { No }\end{array}$ & $\begin{array}{l}1 \\
11\end{array}$ & $\begin{array}{l}8.33 \\
91.67\end{array}$ \\
\hline 7 & $\begin{array}{l}\text { Hospital offer staff } \\
\text { other than cash } \\
\text { benefits }\end{array}$ & $\begin{array}{l}\text { Yes } \\
\text { No }\end{array}$ & 6 & $\begin{array}{l}50.00 \\
50.00\end{array}$ \\
\hline 8 & $\begin{array}{l}\text { Service year of the } \\
\text { facility }\end{array}$ & $\begin{array}{l}<5 \text { years } \\
\geq 5 \text { years }\end{array}$ & $\begin{array}{l}8 \\
4\end{array}$ & $\begin{array}{l}66.67 \\
33.33\end{array}$ \\
\hline 9 & Level of the facility & $\begin{array}{l}\text { Primary } \\
\text { General } \\
\text { Tertiary }\end{array}$ & $\begin{array}{l}10 \\
1 \\
1\end{array}$ & $\begin{array}{l}83.33 \\
8.33 \\
8.33\end{array}$ \\
\hline 10 & Patient waiting time & $\begin{array}{l}<30 \mathrm{~min} \\
\geq 30 \mathrm{~min}\end{array}$ & $\begin{array}{l}2 \\
10\end{array}$ & $\begin{array}{l}16.67 \\
83.33\end{array}$ \\
\hline
\end{tabular}

Note: *Does not include overtime, risk, and duty payments.

The mean \pm standard deviation (SD) score of overall technical efficiency, pure technical efficiency, and scale efficiency of the hospitals were $0.741( \pm 0.278), 0.92$ $( \pm 0.142)$, and $0.795( \pm 0.24)$, respectively (Table 4$)$.

\section{The Projections on Input Reduction and Output Escalation}

The study finding indicated that hospitals wasted $3.6 \%$, $9.8 \%$, and $6.2 \%$ of the salary expenditure, non-salary 
Table 2 Environmental Factors of Public Hospitals Towards Maternal Health Service at the Northwest of ANRS, Ethiopia, 2020 ( $N=12$ DMUs)

\begin{tabular}{|l|l|l|l|l|}
\hline No & Variables & Category & $\begin{array}{l}\text { Frequency } \\
(\mathbf{N})\end{array}$ & $\begin{array}{l}\text { Percent } \\
(\%)\end{array}$ \\
\hline 1 & $\begin{array}{l}\text { Total catchment } \\
\text { population }\end{array}$ & $<1,000,000$ & 7 & 58.33 \\
\hline 2 & $\begin{array}{l}\text { The distance of the } \\
\text { hospital from the } \\
\text { capital of the } \\
\text { district }\end{array}$ & $<100 \mathrm{KM}$ & 10 & 41.67 \\
\hline 3 & $\begin{array}{l}\text { Presence of nearby } \\
\text { health facility* }\end{array}$ & $\begin{array}{l}\text { Yes } \\
\text { No }\end{array}$ & $\begin{array}{l}10 \\
2\end{array}$ & $\begin{array}{l}83.33 \\
16.33\end{array}$ \\
\hline
\end{tabular}

Note: *Within $2 \mathrm{~km}$ distance.

expenditure, and beds, respectively, to produce the amount of ANC, delivery, and PNC service they provided. The expended amount of inputs was needed to produce $11.7 \%$, $13.5 \%$, and $13.9 \%$ more ANC, delivery, and PNC services than what they already produced (Table 5).

\section{Factors Associated with Technical Efficiency}

The study revealed that a year increase in the head's managerial experience increases the hospital's technical efficiency score by 0.031 (95\% CI: 0.005, 0.05). The hospital run by a head who had a master's and above educational status scored 0.219 (95\% CI: 0.121, 0.317) more technical efficiency than hospitals run by heads who had a bachelor's degree. A unit increase in the hospital's service year increases the technical efficiency score by 0.09 (95\% CI: $0.051,0.129)$. Another health facility that gives maternal health service within a $2 \mathrm{~km}$ distance increases the hospital's technical efficiency score by 0.497 (95\% CI: 0.344, 0.651). A 100,000 increase in the hospital catchment population decreases the hospital's technical efficiency score by 0.0524 (95\% CI: $-0.101,-0.0036)$ (Table 6).

\section{Discussion}

In this study, the mean pure technical efficiency score of the public hospitals were $0.92( \pm 0.14 \mathrm{SD})$. When the hospitals perform in their best managerial performance, $8 \%$ of resources would be saved for the constant volume of outputs produced. On the other side, the average pure technical efficiency score of the inefficient hospitals was $80.8 \%$ $( \pm 17 \%$ SD). This means the inefficient hospitals need to reduce $19.2 \%$ of the resource allocation to be fully technical efficient as their peers on the frontier.

This finding is in line with the study conducted in Oromia $75 \%{ }^{19}$ However, it is higher than the studies conducted in Ethiopia's public primary hospitals, $55 \%{ }^{20}$ and Tigray $42 \% .{ }^{35}$ This might be due to the change in time and demography that makes the current study high client flow, which is not proportional to resource allocation compared with the previous studies.

The finding of this study exhibits similarity with the studies conducted in India, ${ }^{16}$ Colombia, ${ }^{36}$ and Sierra Leone, ${ }^{15}$ with the technical efficiency scores of the inefficient hospitals 0.79 ( $\pm 0.12 \mathrm{SD}), 0.75$, and 0.63 ( $\pm 0.18 \mathrm{SD})$, respectively. On the other hand, it is higher than the study conducted in Bangladesh, 0.63. ${ }^{14}$

The study also showed that 7 (58.3\%) of the hospitals were exhibiting pure technical efficiency, which is attributable to the facility's managerial performance. The number of pure technical efficient hospitals was in line with the studies conducted in India ${ }^{16}$ and Sierra Leone, ${ }^{15}$ where $50 \%$ and $63 \%( \pm 18 \% \mathrm{SD})$ of hospitals were technical efficient, respectively.

However, the finding is lower than the studies conducted in Oromia, in which $78.8 \%$ of hospitals perform pure technical efficiency. ${ }^{19}$ This might be due to the large

Table 3 Inputs Used and Outputs Produced on Maternal Health Service Provision at Public Hospitals in Northwest of ANRS, Ethiopia, 2020 ( $N=12$ DMUs)

\begin{tabular}{|l|l|l|l|l|l|l|}
\hline & Variables & Total & Mean & SD & Min & Max \\
\hline Inputs & Salary expenditure (US\$) & $2,303,706$ & $191,975.5$ & $362,812.4$ & $31,463.13$ & $1,337,061$ \\
& Non-salary expenditure (US\$) & $477,534.5$ & $39,794.54$ & $75,929.69$ & 4480.58 & 276,202 \\
& No of beds & 297 & 24.75 & 33.78 & 6 & 130 \\
\hline \multirow{2}{*}{ Outputs } & ANC & 31,892 & 2657.67 & 3812.40 & 437 & 14,208 \\
& Skilled delivery & 26,723 & 2226.92 & 2985.83 & 497 & 11,066 \\
& PNC & 16,346 & 1362.17 & 1566.63 & 48 & 6044 \\
\hline
\end{tabular}


$\square$ CRS TE $\square$ VRS TE $\square$ Scale efficiency

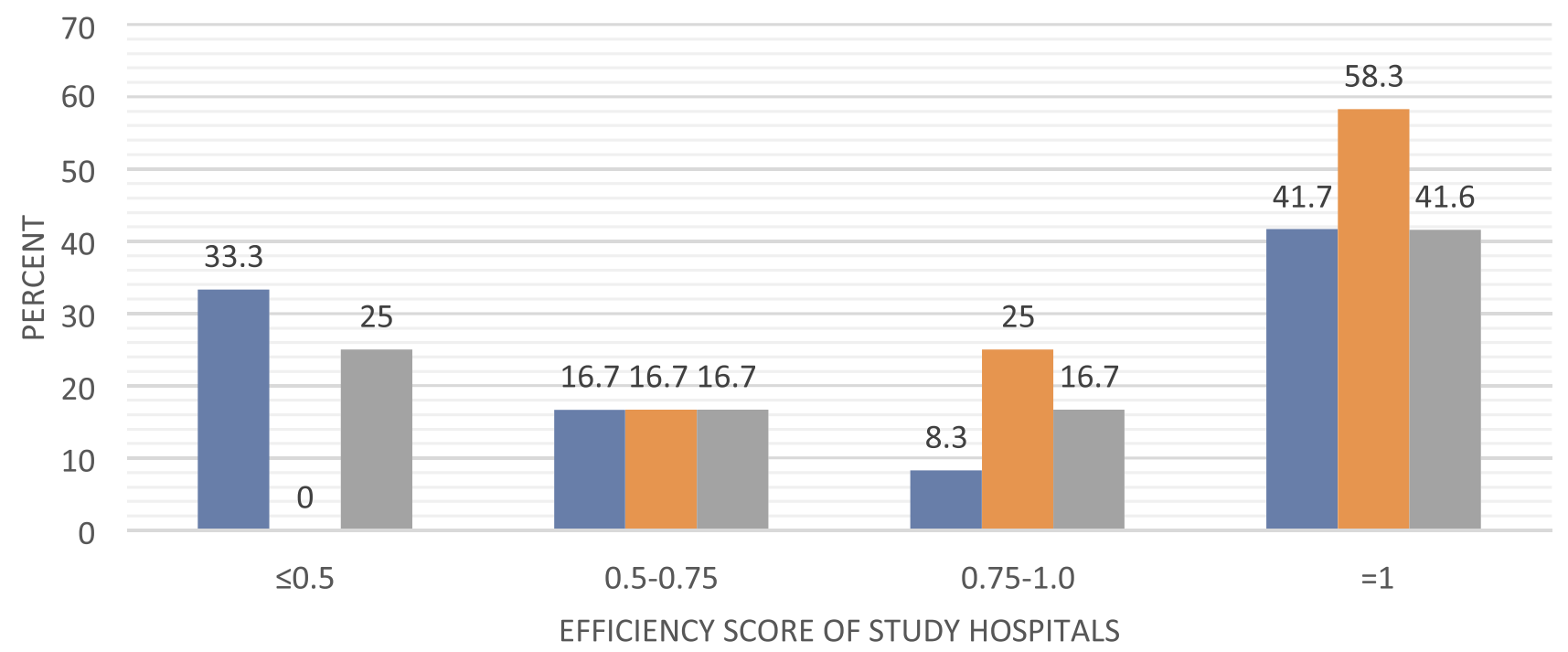

Figure I Efficiency score of public hospitals towards the provision of maternal health service in Northwest of ANRS, Ethiopia, 2020 (N = I2DMUs).

(three more) number of outputs were used. So that when the number of outputs increases, the high number of DMUs would be technically efficient. ${ }^{37}$ This finding is lower than with the research conducted in Bangladesh, where $79 \%$ of the hospitals were technically efficient. ${ }^{14}$ This might be due to taking the outpatient visit as one of the outputs which were not included in this study as one of the least resource-intensive departments in hospitals. ${ }^{38}$ But, it is higher than the findings from the studies conducted in Kenya, ${ }^{39}$ Nigeria, ${ }^{40}$ Sierra Leone, ${ }^{15}$ and

Table 4 Efficiency Score of Public Hospitals Towards the Provision of Maternal Health Service in Northwest of ANRS, Ethiopia, 2020 ( $\mathrm{N}=$ I2DMUs)

\begin{tabular}{|l|l|l|l|l|}
\hline DMUs & $\begin{array}{l}\text { CRS } \\
\text { TE }\end{array}$ & $\begin{array}{l}\text { VRS } \\
\text { TE }\end{array}$ & $\begin{array}{l}\text { Scale } \\
\text { Efficiency }\end{array}$ & $\begin{array}{l}\text { Returns to } \\
\text { Scale }\end{array}$ \\
\hline $\mathrm{H} 0 \mathrm{I}$ & 0.447 & 1.000 & 0.447 & DRS \\
$\mathrm{H} 02$ & 0.689 & 0.720 & 0.957 & DRS \\
$\mathrm{H} 03$ & 0.900 & 1.000 & 0.900 & DRS \\
$\mathrm{H} 04$ & 0.333 & 0.585 & 0.569 & IRS \\
$\mathrm{H} 05$ & 1.000 & 1.000 & 1.000 & - \\
$\mathrm{H} 06$ & 1.000 & 1.000 & 1.000 & - \\
$\mathrm{H} 07$ & 0.326 & 0.789 & 0.460 & IRS \\
$\mathrm{H} 08$ & 1.000 & 1.000 & 1.000 & - \\
$\mathrm{H} 09$ & 1.000 & 1.000 & 1.000 & - \\
$\mathrm{H} 10$ & 0.492 & 0.995 & 0.495 & IRS \\
HII & 0.671 & 0.950 & 0.707 & IRS \\
HI2 & 1.000 & 1.000 & 1.000 & - \\
Mean & 0.741 & 0.920 & 0.795 & \\
SD & 0.278 & 0.142 & 0.240 & \\
\hline
\end{tabular}

Malaysia, ${ }^{41}$ in which $11.76 \%, 33.3 \%, 41 \%$, and $37.5 \%$ of hospitals were pure technical efficient respectively. This discrepancy may be because all are conducted on a higher number of hospitals, which is explained by high observation leading to a low-efficiency level. ${ }^{32}$

The finding is higher than the studies conducted in China, ${ }^{17}$ Kenya, ${ }^{39}$ Zambia, ${ }^{35}$ and Mexico, ${ }^{18}$ with the average pure technical efficiency scores of $0.78,49.9$ ( $\pm 0.32 \mathrm{SD}), 0.42$, and 0.30 , respectively. This may be due to the number of observations performed by the listed studies. However, it is lower than the studies conducted in Colombia at $0.96{ }^{36}$ This may be due to the difference in the study setting.

The study showed the scale efficiency score of the hospitals was $0.79( \pm 0.24 \mathrm{SD})$. This means when the scale inefficient hospitals operate on their optimal size; the total inputs would be decreased by $21 \%$ without changing the number of outputs produced. Among all, 5 $(41.67 \%)$ were scale efficient, and $7(58.33 \%)$ were scale inefficient. Among the scale inefficient hospitals, 3 (25\%) were operating high for their operation size, and 4 $(33.33 \%)$ were running low for their size of production.

The study showed that the overall amounts of salary and non-salary expenditures were US\$ $191,975.10$ and US\$ $39,794.50$, respectively but, the maximum amount of salary and non-salary expenditures they need to use to produce the number of maternal health service they already produced was US\$ $185,141.60$ and US\$ $35,907.70$. This means the hospitals included in this study were wasted US\$ 6833.50 
Table 5 Input Reduction and Output Escalation Projections to Make Inefficient Hospitals More Efficient in the Northwest of ANRS, Ethiopia, 2020 ( $\mathrm{N}=12$ DMUs)

\begin{tabular}{|c|c|c|c|c|c|c|c|}
\hline & & \multicolumn{3}{|l|}{ Inputs } & \multicolumn{3}{|l|}{ Outputs } \\
\hline & & Salary (\$) & Non-Salary (\$) & Beds (N) & ANC (N) & Delivery (N) & PNC (N) \\
\hline \multirow[t]{3}{*}{$\mathrm{HOI}$} & Original & $I, 337,06 \mathrm{I}$ & 276,202 & 130 & 14,208 & 11,066 & 6044 \\
\hline & Projected & $|, 337,06|$ & 276,202 & 130 & 14,208 & 11,066 & 6044 \\
\hline & Difference & $0 \%$ & $0 \%$ & $0 \%$ & $0 \%$ & $0 \%$ & $0 \%$ \\
\hline \multirow[t]{3}{*}{$\mathrm{H} 02$} & Original & 104,253 & 7389.4 & 14 & 1016 & 1203 & 1215 \\
\hline & Projected & $75,081.3$ & 5321.7 & 8.29 & 1765.3 & 1608.5 & 1215 \\
\hline & Difference & $-27.9 \%$ & $-27.9 \%$ & $-40.7 \%$ & $73.7 \%$ & $33.7 \%$ & $0 \%$ \\
\hline \multirow[t]{3}{*}{$\mathrm{H} 03$} & Original & 125,888 & $19,151.1$ & 20 & 2916 & 1525 & 1649 \\
\hline & Projected & 125,888 & $19,151.1$ & 20 & 2916 & 1525 & 1649 \\
\hline & Difference & $0 \%$ & $0 \%$ & $0 \%$ & $0 \%$ & $0 \%$ & $0 \%$ \\
\hline \multirow[t]{3}{*}{$\mathrm{H} 04$} & Original & 83,049 & $|3,2| 8.7$ & 21 & 437 & 634 & 589 \\
\hline & Projected & 48,561 & 5272.13 & 12 & 1311.9 & 1222.5 & 1012 \\
\hline & Difference & $-41.5 \%$ & $-60.1 \%$ & $-42.8 \%$ & $200.2 \%$ & $92.8 \%$ & $71.8 \%$ \\
\hline \multirow[t]{3}{*}{$\mathrm{H} 05$} & Original & 155,835 & 51,590 & 25 & 4539 & 4424 & 48 \\
\hline & Projected & 155,835 & 51,590 & 25 & 4539 & 4424 & 48 \\
\hline & Difference & $0 \%$ & $0 \%$ & $0 \%$ & $0 \%$ & $0 \%$ & $0 \%$ \\
\hline \multirow[t]{3}{*}{$\mathrm{H} 06$} & Original & 32,559 & $34,788.9$ & 25 & 1530 & 1423 & 1472 \\
\hline & Projected & 32,559 & $34,788.9$ & 25 & 1530 & 1423 & 1472 \\
\hline & Difference & $0 \%$ & $0 \%$ & $0 \%$ & $0 \%$ & $0 \%$ & $0 \%$ \\
\hline \multirow[t]{3}{*}{$\mathrm{H} 07$} & Original & 71,452 & 36,235 & 14 & 609 & 519 & 521 \\
\hline & Projected & $56,348.1$ & 5086 & 11 & $144 \mid .7$ & 1332.9 & 1068.2 \\
\hline & Difference & $-21.1 \%$ & $-85.9 \%$ & $-21.4 \%$ & $136.7 \%$ & $156.8 \%$ & $105 \%$ \\
\hline \multirow[t]{3}{*}{$\mathrm{H} 08$} & Original & 31,463 & 5680.1 & 15 & 1027 & 980 & 891 \\
\hline & Projected & 31,463 & 5680.1 & 15 & 1027 & 980 & 891 \\
\hline & Difference & $0 \%$ & $0 \%$ & $0 \%$ & $0 \%$ & $0 \%$ & $0 \%$ \\
\hline \multirow[t]{3}{*}{ H09 } & Original & 147,356 & $13,555.2$ & 6 & 1834 & 2154 & 1715 \\
\hline & Projected & 147,356 & $13,555.2$ & 6 & 1834 & 2154 & 1715 \\
\hline & Difference & $0 \%$ & $0 \%$ & $0 \%$ & $0 \%$ & $0 \%$ & $0 \%$ \\
\hline \multirow[t]{3}{*}{$\mathrm{HIO}$} & Original & $76,099.2$ & 8323.61 & 8 & 901 & 605 & 504 \\
\hline & Projected & $75,7 \mid 2.3$ & 4624.4 & 7.9 & 1764 & 1607 & 1206 \\
\hline & Difference & $-0.5 \%$ & $-44.4 \%$ & $-1.25 \%$ & $95.7 \%$ & $165.6 \%$ & $139 \%$ \\
\hline \multirow[t]{3}{*}{$\mathrm{HII}$} & Original & 56,944 & 6918.8 & 12 & 1010 & 497 & 449 \\
\hline & Projected & $54,093.4$ & 5140 & 11.4 & 1404.2 & 1300.9 & 1052.1 \\
\hline & Difference & $-5 \%$ & $-25.7 \%$ & $-5 \%$ & $39 \%$ & $161 \%$ & $134 \%$ \\
\hline \multirow[t]{3}{*}{$\mathrm{HI} 2$} & Original & $8 I, 74 I .5$ & 4480.6 & 7 & 1865 & 1693 & 1249 \\
\hline & Projected & $8 I, 741.5$ & 4480.6 & 7 & 1865 & 1693 & 1249 \\
\hline & Difference & $0 \%$ & $0 \%$ & $0 \%$ & $0 \%$ & $0 \%$ & $0 \%$ \\
\hline \multirow[t]{3}{*}{ Mean } & Original & $191,975.1$ & $39,794.5$ & 24.8 & 2657.7 & 2226.9 & 1362.2 \\
\hline & Projected & $185,141.6$ & $35,907.7$ & 23.2 & 2967.8 & 2528.1 & 1551.8 \\
\hline & Difference & $-3.6 \%$ & $-9.8 \%$ & $-6.2 \%$ & $11.7 \%$ & $13.5 \%$ & $13.9 \%$ \\
\hline
\end{tabular}


Table 6 Factors Significantly Associated with a Technical Efficiency Score of Public Hospitals Towards the Provision of Maternal Health Service in Northwest of ANRS, Ethiopia, 2020 ( $N=$ I2DMUs)

\begin{tabular}{|c|c|c|c|c|c|}
\hline Variables & Category & Coefficient & $\mathbf{T}$ & P-value & $95 \% \mathrm{Cl}$ \\
\hline CEO's managerial experience in years & $\mathrm{N}$ & 0.031 & 2.81 & $0.026 *$ & $(0.005,0.05)$ \\
\hline Educational status of the CEO ( $\geq$ Master.) & $\mathrm{D}$ & 0.219 & 5.29 & $0.001 *$ & $(0.121,0.317)$ \\
\hline Service year of the hospital & $\mathrm{N}$ & 0.090 & 5.48 & $0.001 *$ & $(0.05 I, 0.129)$ \\
\hline Presence of another health facility in $\leq 2 \mathrm{~km}$ & $D$ & 0.497 & 7.66 & $0.000 *$ & $(0.344,0.651)$ \\
\hline Total number of the catchment population & $\mathrm{N}$ & $-5.24 e^{-07}$ & -2.54 & $0.039 *$ & $\left(-1.01 \mathrm{e}^{-06},-3.6 \mathrm{e}^{-08}\right)$ \\
\hline Constant & & 0.036 & 0.34 & 0.743 & $(-0.218,0.292)$ \\
\hline Sigma & & 0.039 & & & $(0.007,0.070)$ \\
\hline Log-likelihood & & 7.18 & & & \\
\hline Number of observations & & 12 & & & \\
\hline Chi square & & 23.82 & & & \\
\hline
\end{tabular}

Note: *significant with p-value $<0.05$.

Abbreviations: $D$, dummy variable; $N$, numeric variable.

and US\$ 3886.8 for salary and non-salary expenditures, respectively. This could be the health expenditure for 323 clients according to the seventh Ethiopian health account per capita health expenditure of US\$33.2 ${ }^{5}$ and for 125 clients according to the WHO recommendation per capita, health expenditure for low-income countries US $\$ 86 .{ }^{42}$

The study also revealed that a year increase in the managerial experience of the CEO increases the hospital technical efficiency score by 0.031 (95\% CI: $0.005,0.05)$. The hospital run by heads who had a master's and above educational status scored 0.219 (95\% CI: 0.121, 0.317) more technical efficiency score than hospitals run by heads who had a bachelor's degree. This might be as experience and level of education increases, the leadership and managerial skill of managers will be improved, which directly contribute to the wise use of resources.

A unit increase in the service year of the hospital increases the technical efficiency score by 0.09 (95\% CI: 0.051, 0.129), which is also the finding of the study conducted in Oromia, Ethiopia, ${ }^{19}$ where the service year of the facility increases the technical efficiency score by 0.02 . This might be due to those high served hospitals can more preserve human power, and they have a more adaptive and sustainable work environment through the consistent managerial team.

The presence of another health facility that gives maternal health service within a $2 \mathrm{~km}$ distance increases the technical efficiency score of the hospital by 0.497 (95\% CI: 0.344, 0.651), which is supported by the study conducted in Palestine. ${ }^{43}$ The study conducted in Burkina Faso $^{34}$ also suggests an increased distance between the next health facility decreases the technical efficiency score of the hospital by 0.107 . The reason might be the hospital's patient load would be shared by the adjacent health facilities, which may reduce their facilities burden.

A 100,000 increase in the catchment population of the hospital decreases the hospital's technical efficiency score by 0.0524 (95\% CI: $-0.101,-0.0036)$. It is in line with the study conducted in Greece. ${ }^{44}$ But, it is contrary to the findings of the studies conducted in Henan, China, ${ }^{45}$ and Oromia Ethiopia. ${ }^{19}$ The catchment population of hospitals increases the technical efficiency score by 0.104 and 0.056 , respectively. The reason could be the hospitals in this study were very close to the capital city of the district, with $83.3 \%$ had $<100 \mathrm{~km}$. So, the bypass of the hospitals to a higher-level lead to low health service production in the hospitals.

\section{Limitations of the Study}

Even though this study has many implications for decision making, it has its limitations, which need to be considered while interpreting and concluding the result. First, the study includes only the public hospitals and so will never be construed for the private hospitals as their primary goal is different. Second, the quality adjustment was not made in the study, and it may have a constraint on the comparison, which is because the DEA analysis has no room for quality adjustment. Third, the study used inputs and outputs for a single year, so the efficiency scores may be changed when the data is changed.

Finally, even though health facilities perform many outputs with many inputs, it is challenging to incorporate all the inputs and outputs for analysis. So, the result of this study may be changed when the inputs and outputs of the research are changed. Despite those limitations, since the study applied the DEA for technical efficiency 
measurement, the finding can be used to evaluate the performance evaluation in the health care system and the benchmark for the subsequent studies.

\section{Conclusion}

The study revealed that the pure technical efficiency score of public hospitals in Northwest Ethiopia is high. More than half of the public hospitals in Northwest Ethiopia were scored $100 \%$. The study also showed that the managerial experience and educational status of the head of the hospital, service year of the hospital, and the presence of nearby health facilities providing maternal health services were identified to improve the technical efficiency of the public hospitals. In contrast, the increased catchment population of the service area was identified to diminish the technical efficiency of the hospitals.

For the higher officials, it is better to expand health facilities to decrease the patient load, to hire more experienced, and build the capacity of facility heads. Besides, experience between experienced and less experienced hospitals is advisable.

For the next researchers, efficiency measurement of the health systems of Ethiopia is one of the untouched areas of study. So, it is better to evaluate the efficiency performance of the DMUs in the health system. If possible, incorporating a higher number of observations and with longitudinal data will generate strong evidence for crucial decision making on maternal health services towards the efficient use of scarce health resources in low-income countries like Ethiopia.

\section{Abbreviations}

ANC, Antenatal Care; CEO, Chief Executive Officer; CRS, Constant Returns to Scale; DEA, Data Envelopment Analysis; DMU, Decision-Making Unit; DRS, Decreasing Returns to Scale; IRS, Increasing Returns to Scale; PNC, Postnatal Care; SD, Standard Deviation; SSA, Sub Saharan Africa; TE, Technical Efficiency; VRS, Variable Returns to Scale; WHO, World Health Organization.

\section{Data Sharing Statement}

The input and output data used in this study is provided as Supplementary Material. But the whole data used will be acquired on the formal request to the correspondent author.

\section{Ethics Approval and Consent to Participate}

Ethical clearance was obtained from the ethical review committee of the Institute of Public Health, the University of Gondar, with reference number IPH/837/06/12. A supporting letter was received from the Amhara Public Health Institute, where districts in Northwest Ethiopia are accounted for. We described the objective of the study and obtained written informed consent from the head of each hospital.

\section{Acknowledgments}

We very much appreciated the staff of the Department of Health Systems and Policy for their invaluable support throughout the accomplishment of the thesis work. We would also thank the study facilities for their cooperation during the data collection, and finally, our gratitude goes to the data collectors.

\section{Author Contributions}

All authors made a significant contribution to the work reported, whether that is in the conception, study design, execution, acquisition of data, analysis and interpretation, or in all these areas; took part in drafting, revising or critically reviewing the article; gave final approval of the version to be published; have agreed on the journal to which the article has been submitted; and agree to be accountable for all aspects of the work.

\section{Funding}

There is no funding for this manuscript.

\section{Disclosure}

The authors declare that they have no conflicts of interest for this work.

\section{References}

1. World Health Organization. World health statistics 2018: monitoring health for the SDGs (sustainable development goals). Geneva: World Health Organization; 2018.

2. World Health Organization. Trends in maternal mortality: 1990-2015: estimates from WHO, UNICEF, UNFPA, World Bank Group and the United Nations Population Division: executive summary. World Health Organization; 2015.

3. Central Statistical Agency. Ethiopian Demographic and Health Survey. Addis Ababa, Ethiopia; 2016.

4. GA UJDfSDGNY, NY, USA. Transforming our world: the 2030 Agenda for Sustainable Development; 2015.

5. Ethiopian Federal Ministry of Health. The seventh ethiopian national health account. Addis Ababa, Ethiopia. 2016/September 17-18; 2019. 
6. Lambo E, Sambo L. Health sector reform in sub-Saharan Africa: a synthesis of country experiences. East Afr Med J. 2003;80(6):S1S20.

7. Zelelew H. Health Care Financing Reform in Ethiopia: Improving Quality and Equity. Vol. 20. Bethesda (MD): Health Systems; 2018:20.

8. Alebachew A, Yusuf Y, Mann C, Berman P. Ethiopia's Progress in health financing and the contribution of the 1998 health care and financing strategy in Ethiopia. MA, Addis Ababa: Harvard TH Chan School of Public Health and Breakthrough International Consultancy, PLC; 2015.

9. Serván-Mori E, Chivardi C, MÁ M, Nigenda G. A longitudinal assessment of technical efficiency in the outpatient production of maternal health services in México. Health Policy Plan. 2018;33 (8):888-897. doi:10.1093/heapol/czy074

10. World Health Organization. Health systems financing. Geneva, Switzerland: World Health Organization; 2017. Available from: https://www.who.int/healthsystems/topics/financing/en/. Accessed December 11, 2020.

11. FMoH E. Health Sector Transformation Plan. HSTP 2015/16-2019/ 20; August, 2015.

12. Australia. Steering Committee for the Review of Commonwealth/ State Service Provision Scales B. Data envelopment analysis: a technique for measuring the efficiency of government service delivery: industry Commission; 1997.

13. Cooper WW, Seiford LM, Zhu J. Data envelopment analysis. In: Cooper WW, Seiford LM, Zhu J, editors. Handbook on Data Envelopment Analysis. Boston, MA: Springer US; 2004:1-39.

14. Ahmed S, Hasan MZ, Laokri S, et al. Technical efficiency of public district hospitals in Bangladesh: a data envelopment analysis. Cost Eff Res Allocation. 2019;17(1):15.

15. Renner A, Kirigia JM, Zere EA, et al. Technical efficiency of peripheral health units in Pujehun district of Sierra Leone: a DEA application. BMC Health Serv Res. 2005;5(1):77. doi:10.1186/14726963-5-77

16. Ram Jat T, San Sebastian MJ. Technical efficiency of public district hospitals in Madhya Pradesh, India: a data envelopment analysis. Global Health Action. 2013;6(1):21742.

17. Zhang T, Lu W, Tao HJ. Efficiency of health resource utilization in primary-level maternal and child health hospitals in Shanxi Province, China: a bootstrapping data envelopment analysis and truncated regression approach. BMC Health Serv Res. 2020;20(1):1-9.

18. Serván-Mori E, Chivardi C, Mendoza MÁ, Nigenda GJ. planning. A longitudinal assessment of technical efficiency in the outpatient production of maternal health services in México. Health Policy Plann. 2018;33(8):888-897.

19. Yitbarek K, Adamu A, Tsega G, et al. Technical efficiency of maternal and reproductive health services in public Hospitals of Oromia Regional State, Ethiopia. Health Serv Insights. 2019;12:1178632919837630.

20. Mann C, Adugna M, Berman P Measuring efficiency of public primary hospitals in Ethiopia. Boston, Massachusetts and Addis Ababa, Ethiopia: Harvard T.H. Chan School of Public Health and Federal Democratic Republic of Ethiopia Ministry of Health; 2016.

21. FMOH A. Health Sector Development Program - IV 2010/11-2014/ 15. Federal Democratic Republic of Ethiopia Addis Ababa; 2010.

22. Ethiopian Standard Agency. Primary Hospital - Requirements. Addis Ababa, Ethiopia: Ethiopian Federal Ministry of Health; 2012.

23. Sambo L, Chatora R, Goosen E. Tools for Assessing the Operationality of District Health Systems. Brazzaville: World Health Organization, Regional Office for Africa; 2003.

24. Cooper WW, Seiford LM, Zhu J. Handbook on Data Envelopment Analysis. Springer Science \& Business Media; 2011.
25. Golany B, Roll Y. An application procedure for DEA. Omega. 1989;17(3):237-250. doi:10.1016/0305-0483(89)90029-7

26. Kirigia JM, Asbu EZ. Technical and scale efficiency of public community hospitals in Eritrea: an exploratory study. Health Econ Rev. 2013;3(1):6. doi:10.1186/2191-1991-3-6

27. Ethiopian Federal Ministry of Health. DHIS2 User Guide. Addis Ababa: FMoH; 2006.

28. National Bank of Ethiopia. Commercial Banks' Exchange Rate National Bank Addis Ababa. National Bank Of Ethiopia; 2019 Available from: https://nbebank.com/commercial-banks-exchangerate/. Accessed December 11, 2020.

29. Ozcan YA. Health Care Benchmarking and Performance Evaluation. Springer; 2008.

30. Cooper WW, Seiford LM, Zhu J. Data envelopment analysis: history, models, and interpretations. In: Handbook on Data Envelopment Analysis. Boston, MA: Springer; 2011:1-39.

31. Jacobs R, Smith PC, Street A. Measuring Efficiency in Health Care: Analytic Techniques and Health Policy. Cambridge University Press; 2006.

32. Coelli T. Productivity Analysis UoNE, Australia. A guide to DEAP version 2.1: a data envelopment analysis (computer) program. Centre Eff Productivity Anal. 1996;96(08).

33. Charnes A, Cooper WW, Rhodes E. Measuring the efficiency of decision making units. Eur J Oper Res. 1978;2(6):429-444. doi:10.1016/0377-2217(78)90138-8

34. Marschall P, Flessa S. Efficiency of primary care in rural Burkina Faso. A two-stage DEA analysis. Health Econ Rev. 2011;1(1):5.

35. Achoki T, Hovels A, Masiye F, Lesego A, Leufkens H, Kinfu Y. Technical and scale efficiency in the delivery of child health services in Zambia: results from data envelopment analysis. BMJ Open. 2017;7(1):e012321.

36. Ruiz-Rodriguez M, Rodriguez-Villamizar LA, Heredia-Pi IJ. Technical efficiency of women's health prevention programs in Bucaramanga, Colombia: a four-stage analysis. BMC Health Serv Res. 2016;16(1):576.

37. Nash C. Handbook of Research Methods and Applications in Transport Economics and Policy. Edward Elgar Publishing; 2015.

38. Agarwal A, Mann C, Abdella E, Mitiku W, Alebachew A, Berman P. Recurrent costs in primary health care in Ethiopia: facility and disease specific unit costs and their components in government primary hospitals and health centers. BMC Health Serv Res. 2020;20:1-12.

39. Makheti AJ. Technical efficiency in public health facilities in Meru County: Dea Analysis. Health Econ Outcome Res. 2017;3(4):1-6.

40. Aloh HE, Onwujekwe OE, Ichoku HE, Osigwe AC. Scaling up maternal and child healthcare delivery among mission hospitals in Southeast Nigeria: an Empirical application of data envelopment analysis for setting benchmarks and targets. Afr J Reprod Health. 2019;23(3):57-67.

41. Arinah W, Juni MH, Ying LP, Ghani JA, Kamarudin F. Technical efficiency assessment of maternal health services in Negeri Sembilan, Malaysia using data envelopment analysis. Int J Pub Health Clin Sci. 2019;6(4):79-95.

42. World Health Organization. Global Spending on Health: A World in Transition. World Health Organization; 2019.

43. Sultan WI, Crispim J. Measuring the efficiency of Palestinian public hospitals during 2010-2015: an application of a two-stage DEA method. BMC Health Serv Res. 2018;18(1):381.

44. Kounetas K, Mitropoulos I, Mitropoulos P. Factors affecting primary health care centers' economic and production efficiency. Ann Oper Res. 2015:1-16.

45. Cheng Z, Tao H, Cai M, et al. Technical efficiency and productivity of Chinese county hospitals: an exploratory study in Henan province, China. BMJ open. 2015;5(9). 


\section{Publish your work in this journal}

Risk Management and Healthcare Policy is an international, peerreviewed, open access journal focusing on all aspects of public health, policy, and preventative measures to promote good health and improve morbidity and mortality in the population. The journal welcomes submitted papers covering original research, basic science, clinical \& epidemiological studies, reviews and evaluations, guidelines, expert opinion and commentary, case reports and extended reports. The manuscript management system is completely online and includes a very quick and fair peer-review system, which is all easy to use. Visit http://www.dovepress.com/testimonials.php to read real quotes from published authors. 